\title{
O conceito de consciência moral como chave de uma interpretação fenomenológica da vontade de potência
}

\author{
Ricardo Pedroza Vieira*
}

Resumo: $\mathrm{O}$ artigo tem por objetivo realizar uma análise do conceito de consciência moral (Gewissen) no pensamento de Nietzsche e mostrar uma conexão entre este conceito e a vontade de potência. Esta relação circunscreve, em seu interior, como conceito derivado, a má consciência (schlechtes Gewissen), e abre um horizonte fenomenológico de interpretação para a vontade de potência. Palavras-chave: consciência moral, fenomenologia, má consciência, vontade de potência.

* Professor do Colégio Pedro II, Rio de Janeiro, RJ, Brasil.

ORCID https://orcid.org/0000-0002-4290-7407

Correio eletrônico: ricardopvieira@gmail.com 
Vieira, R. P.

Sou um vidente: mas a consciência moral implacável segue o meu olhar: assim, sou também o intérprete de minhas visões ${ }^{l}$.

\section{Introdução}

O título deste ensaio anuncia o projeto de uma interpretação fenomenológica do conceito de vontade de potência. Fenomenológica, no sentido de que se pretende mostrar que este conceito não está comprometido com a construção teórica de um sistema ou estrutura a partir de onde se possa explicar os fenômenos que compõem a realidade. Em vez disso, nota-se uma preocupação em descrever experiências e elaborar interpretações que sinalizem para o âmbito dos fenômenos em seu caráter enigmático e problemático. A tese central que pretendemos expor e justificar é que a consciência moral [Gewissen] é, para Nietzsche, a experiência fundamental a partir da qual se pode identificar na ontologia da vontade de potência um caráter fenomenológico. Admitimos de inicio que a conexão entre consciência moral e vontade de potência no sentido pretendido soa contraintuitiva. Pois vontade de potência é o conceito central da obra mais madura deste autor, e surge precisamente na época em que ele mesmo caracteriza como a de sua "campanha contra a moral" (EH/ EH, Aurora 1, KSA 6.329). Neste contexto, um dos mais célebres livros de Nietzsche, a Genealogia da Moral, apresenta uma crítica contundente precisamente do conceito de consciência moral. A segunda parte deste livro se intitula: "Culpa, má consciência e coisas afins". A certa altura, Nietzsche afirma: "Vejo a má consciência como a profunda doença que o homem teve de contrair (...)" (GM/ GM II, 16, KSA 5.321). Má consciência [schlechtes Gewissen] é uma

1 Nachlass/PF 1883, 13[1], KSA 10.433. Trata-se de um esboço de fala de Zaratustra; a tradução é nossa. Seguimos as traduções em português indicadas na bibliografia, exceto quando indicado em contrário.

194 | Cad. Nietzsche, Guarulhos/Porto Seguro, v.40, n.1, p. 193-219, janeiro/abril, 2019. 
expressão cujo significado aparenta ser próximo ou idêntico ao de consciência moral [Gewissen]. Orbitando a noção de consciência moral aparecem fenômenos como culpa, remorso, arrependimento, e "coisas afins". Consciência moral seria, assim, o rótulo geral para toda esta seara. Em oposição a tudo isto, Nietzsche menciona em outra passagem "(...) aquele mesmo instinto de liberdade (na minha linguagem: a vontade de potência) (...)" (GM/GM, II, 18, KSA 5.326). Vontade de potência seria um conceito relacionado a uma afetividade afirmativa, sadia, criativa, livre das amarras da consciência moral.

Há três pressupostos que sustentam este entendimento da relação entre os conceitos mencionados. 1) A primeira delas é a aproximação entre consciência moral e má consciência e a compreensão da primeira a partir da segunda. 2) Em seguida, sobre a base desta suposição, a contraposição entre consciência moral e vontade de potência. 3) E, por fim, a suposição de que tal contraposição entre vontade de potência e má consciência funcione como uma espécie de dilema moral, que exige denúncia e condenação de uma coisa e apologia ou exortação à outra² .

Estes três pontos já podem ser preliminarmente colocados em questão, simultaneamente, através de uma análise de uma passagem no início do texto da segunda parte da Genealogia da Moral, em que

2 Seria impossível avaliar em detalhe neste ensaio o grau de correspondência ao menos de um número considerável das mais difundidas interpretações de Nietzsche a estes três pontos. Para fins meramente ilustrativos, mencionamos as seguintes. Jaspers e Kaufmann dão pouco destaque à consciência moral e não a distinguem da má consciência em específico; o primeiro (2015) opõe a má consciência à inocência da moral nobre, associada à vontade de poder, e o segundo (1974) aponta a má consciência como um estágio do desenvolvimento psíquico necessário à meta ulterior de sublimação e controle dos instintos. Heidegger não aborda a consciência moral (2007), nem mesmo quando trata do conceito de espírito de vingança (2006). Deleuze (2001), em diálogo explícito com Freud, traça uma detalhada gênese da má consciência a partir do ressentimento e do triunfo das forças reativas sobre as forças ativas, fazendo a ressalva de que as implicações destes conceitos não devem ser circunscritas à psicologia. Pela riqueza de sua abordagem e ênfase na importância dos conceitos, as leituras de inspiração pós-estruturalista ou freudiana da má consciência estão provavelmente entre as mais influentes. Todavia, talvez sejam também as leituras que mais se encaixam nos três pressupostos que destacamos. Nesta linha, Krastanov (2016) oferece um texto notável que coloca a consciência moral em primeiro plano.

Cad. Nietzsche, Guarulhos/Porto Seguro, v.40, n.1, p. 193-219, janeiro/abril, 2019. 
Vieira, R. P.

Nietzsche se refere ao tipo de ser humano que conquistou aquela liberdade, que, como já vimos, está associada à ideia de vontade de potência:

O orgulhoso conhecimento [Wissen] do privilégio extraordinário da responsabilidade, a consciência [Bewusstsein] dessa rara liberdade, desse poder sobre si mesmo e o destino, desceu nele até sua mais íntima profundeza e tornou-se instinto [Instinkt], instinto dominante - como chamará ele a esse instinto dominante, supondo que necessite de uma palavra para ele? Mas não há dúvida: este homem soberano o chama de sua consciência moral [Gewissen]... Sua consciência moral?... Já se percebe que o conceito de "consciência moral", com que deparamos aqui em sua manifestação mais alta, quase desconcertante, tem uma longa história e variedade de formas atrás de si. (GM/GM II, 2-3, KSA 5.294).

A passagem descreve um certo tipo humano que tem um conhecimento [Wissen] a respeito de uma certa responsabilidade. Isto está associado a uma certa consciência [Bewusstsein] da liberdade, uma clareza de compreensão e reflexão a respeito dela. Este conhecimento da liberdade se transforma em instinto e passa a predominar como orientação. Conquista-se, assim, um instinto de liberdade - a vontade de potência? Porém, não se chama este instinto de "vontade de potência". Ele é chamado de "consciência moral". Neste ponto, o texto hesita, prevendo que seu leitor ficará provavelmente desconcertado com as afirmações anteriores, e observa que se trata aqui da "manifestação mais alta" de um conceito que "tem uma longa história e variedade de formas atrás de si". Esta passagem pressupõe, portanto, precisamente o oposto daquelas três suposições que consistem o pano de fundo de uma contraposição entre consciência moral e vontade de potência. Primeiro: a consciência moral não se reduz à má consciência, mas admite uma variedade de formas. Em segundo lugar: ao menos uma destas formas não se encontra contraposta, mas sim intimamente associada à vontade de potência. Em terceiro lugar: o processo pelo qual a vontade de potência chega a

196 | Cad. Nietzsche, Guarulhos/Porto Seguro, v.40, n.1, p. 193-219, janeiro/abril, 2019. 
O conceito de consciência moral como chave de uma interpretação...

se exercer plenamente enquanto instinto de liberdade predominante sobre a vida humana não aparece determinado prioritariamente por uma insistente recusa da má consciência ou de alguma forma qualquer da consciência moral, nem por um ato de arbítrio pelo qual se opte por um determinado modo de vida em detrimento de outro, mas por uma estranha transformação de "conhecimento" [Wissen ] e "consciência" [Bewusstsein] em "instinto". Este último ponto é particularmente ainda mais intrigante à medida que, como discutiremos depois, haja uma conexão especial entre o conceito de consciência e a má consciência.

Apesar das dificuldades do caminho interpretativo que apontamos, ele promete tornar compreensível um aforismo que aqueles três pressupostos não permitem entender: "O que diz tua consciência moral? - Tu deves vir a ser o que tu és" (FW/GC 270, KSA 3.519) ${ }^{3}$.

Para desenvolver a análise da passagem acima citada na Genealogia da moral e elucidar a tese enunciada em nosso título, precisaremos, portanto, analisar mais profundamente cada um dos três pressupostos indicados, e assim discutir ao mesmo tempo as relações entre consciência moral e vontade de potência.

\section{A definição do conceito de consciência moral e sua conexão fundamental com a vontade de potência}

É somente em meio às anotações póstumas da época de elaboração do Assim falava Zaratustra que encontramos uma definição concisa do conceito de consciência moral. Ela afirma: "Consciência moral é o sentir no interior do qual a hierarquia de nossos impulsos nos vem à consciência". ${ }^{4}$ (Nachlass/FP 1883, 15 [51], KSA 10.493).

3 Tradução nossa. Duas análises notáveis deste aforismo encontram-se em Babich (2003) e Visser (2004); ambos o situam como uma chave para o núcleo da ética de Nietzsche e apontam para conexões fundamentais entre consciência moral, tempo e vida, através de um diálogo com a tradição fenomenológica. Porém, não relacionam a consciência moral diretamente à vontade de potência.

4. Tradução nossa.

Cad. Nietzsche, Guarulhos/Porto Seguro, v.40, n.1, p. 193-219, janeiro/abril, 2019. 
Vieira, R. P.

A definição se assenta sobre a ideia de que alguma coisa "vem à consciência [Bewusstsein]" no interior de um "sentir". Diferentes tipos de sentir possibilitam diferentes aparições na consciência. A consciência moral é um tipo de sentir peculiar, que deixa aparecer algo para a consciência que está afinado consigo. Para compreender a especificidade deste sentir, só o que a definição nos oferece como pista é o tipo de coisa que ele deixa aparecer - embora se possa aqui cautelosamente objetar que talvez este não seja o melhor caminho para compreender um "sentir", que tampouco se precisa supor que se reduza apenas a um mero veículo de um determinado tipo de aparição para a consciência, desprovido de qualquer elemento próprio de experiência que exceda o conteúdo desta aparição tomada em abstrato. Esta ressalva é especialmente importante se levarmos em consideração que, se o sentir em questão possibilita um determinado vir a ser na consciência, então ele também se encontra atuante de algum modo antes deste vir a ser se consumar. Em todo caso, levandose em consideração estas cautelas, podemos seguir a pista que nos é fornecida. A consciência moral é um sentir. Quando domina e se faz experimentar vigorosamente, vem à consciência a "hierarquia de nossos instintos". O termo "hierarquia" [Rangordnung] encontrase grifado. Significa que a hierarquia é constitutiva dos instintos: eles não aparecem indiferentemente nivelados, mas como forças articuladas segundo graus de intensidade.

$\mathrm{O}$ que é isto que assim aparece? Certamente seria muito artificial supor que se trate de um juízo formalmente construído, algo assim como dizer a si mesmo: "Sim, constato que tenho tais e tais instintos, dos quais este é hierarquicamente superior àquele". Seria uma suposição estranha e fácil de verificar que nunca ou quase nunca ocorre, embora a linguagem formal da definição que situa este aparecer para nós induza a pensá-lo de maneira excessivamente conceitual ou abstrata. Porém, esta armadilha é comum nos escritos de Nietzsche, e particularmente nas anotações póstumas, cuja concisão

198 Cad. Nietzsche, Guarulhos/Porto Seguro, v.40, n.1, p. 193-219, janeiro/abril, 2019. 
O conceito de consciência moral como chave de uma interpretação...

e precisão conceituais não devem nos fazer esquecer que se trata sobretudo de lembretes e resumos para a retomada de experiências de pensamento que talvez não se encontrem descritas da maneira mais direta e apropriada nestes textos.

Para evitar a armadilha, podemos procurar pensar aquilo que a definição de consciência moral indica com o auxílio de uma formulação de tonalidade bem diversa: "Um temporal estava em nosso ar e a natureza que somos escureceu - pois não tínhamos caminho. A fórmula de nossa felicidade: um Sim, um Não, uma linha reta, uma meta..." (AC/AC 1, KSA 6.169). Trata-se aqui, em primeiro lugar, de descrever diretamente - e não conceituar em geral - um sentir. Isto exige um outro estilo de pensamento. $\mathrm{O}$ recurso a imagens não é, portanto, mera retórica ou propedêutica, mas esforço por uma compreensão apropriada do fenômeno. Sentir-se como imerso em uma tempestade: exposto, vulnerável, sacudido por pancadas de chuva e frio, ansioso por um abrigo que não há. Isto, diz-se, é "não ter caminho", isto é, não ter clareza de orientação, ser sacudido e agredido por afetos diversos, confusos, sem conseguir nem aceitálos nem recusá-los inteiramente, sem saber como haver-se com eles. Todavia, permanece-se na tempestade, abraça-se a tempestade como "a natureza que somos". Este perseverar é um encarar de frente e recusar-se a evadir-se, um deixar a tempestade ser e aparecer tal como é, e assim concentrar-se nela. Por isso, torna-se possível ver com atenção aquilo que algum repentino relâmpago rasga depressa e deixa entrever em meio às pancadas: um Sim e um Não. Atração e repulsa de repente já não se misturam confusamente nem agridem. Sim e Não se tornam claros e distintos, porque um afeto finalmente se mostrou como mais poderoso e se revelou como aquilo para o que os outros afetos geravam obstrução, distração, insensibilidade. Portanto: irrompe, mostra-se uma linha reta, uma meta. Hierarquia entre os impulsos, prioridades entre os afetos: isto só pode chegar a aparecer com plena clareza a partir do sentir da tempestade. Não a 
Vieira, R. P.

partir da negação, repressão ou fuga, mas da afirmação incondicional e concentrada deste sentir emerge algo contrário ao que nele aparecia a princípio.

Este fenômeno, o vir a ser e aparecer da hierarquia dos impulsos, é a consciência moral no sentido mais amplo e fundamental. Tudo que é relativo à consciência moral tem de ser interpretado como componente ou como possibilidade de variação deste fenômeno. Também a má consciência, enquanto uma modalidade de consciência moral, deve ser uma determinada maneira de corresponder a ele. Contudo, antes de avançarmos para situar variações ou desdobramentos da consciência moral, precisamos de uma análise mais sólida daquilo que nos foi indicado pela definição deste termo.

Os elementos básicos sobre os quais se ela erige são: o sentir [Gefuihl], o impulso [Trieb], a consciência [Bewusstsein]. Este horizonte remete à análise da noção de vontade, que podemos encontrar na seção 19 de Para além de bem e mal. Lá, encontramos a seguinte afirmação:

Em terceiro lugar, a vontade não é apenas um complexo de sentir e pensar, mas sobretudo um afeto: aquele afeto do comando [Affekt des Commando's]. O que é chamado "liberdade da vontade" [Freiheit des Willens] é, essencialmente, $\mathrm{o}$ afeto de superioridade [Überlegenheits-Affekt] em relação àquele que tem de obedecer: "eu sou livre, 'ele' tem de obedecer" - esta consciência [Bewusstsein] se esconde em toda vontade, e assim também aquele retesamento da atenção [Spannung der Aufmerksamkeit], o olhar direto que fixa exclusivamente uma coisa, a incondicional valoração que diz "isso e apenas isso é necessário agora", e o que mais for próprio da condição de quem ordena. Um homem que quer - comanda algo dentro de si que obedece, ou que ele acredita que obedece. (JGB/BM, 19, KSA 5.32).

O texto, que se dedicara antes do trecho citado a explorar as noções de sentir e pensar como elementos indissociáveis do querer, aqui situa aquilo que, todavia, é o núcleo do querer: o afeto do comando. Trata-se da experiência da liberdade. Nesta experiência, já

5 Divergimos neste termo da tradução de Paulo César de Souza, que opta por "livre-arbítrio".

$200 \mid$ Cad. Nietzsche, Guarulhos/Porto Seguro, v.40, n.1, p. 193-219, janeiro/abril, 2019. 
O conceito de consciência moral como chave de uma interpretação...

não há um sentir-se empurrado e agredido por afetos confusos. Não há, portanto, um sentimento de ser coagido, isto é, interceptado por algo de que se gostaria de escapar. Em vez desta dimensão de afetos, um afeto de comando, isto é, de "co-mandar" a partir de um Sim que se revelou como o afeto mais poderoso. Sentir é um componente do querer. Significa que sentir é abertura de afetos, que são sempre cada qual uma atração que constitui impulso. Sentir é sentir algum afeto, isto é, querer algo, sentir-se fascinado e atraído em algum grau por alguma coisa. No entanto, entre um afeto e seu impulso, enreda-se a malha de outros afetos e impulsos, em cuja complexidade reside a possibilidade de um curto-circuito. Afeto do comando significa: experiência da desobstrução pela qual um impulso se torna livre para seu próprio afeto e pela qual um afeto se torna "co-determinante" de todos os impulsos, libertando-os para se realizarem nele e como meio para ele. Por isso, a vontade é complexa, mas não é apenas complexidade, e sim, sobretudo, transfiguração de complexidade em simplicidade, autossimplificação.

$\mathrm{O}$ afeto do comando é a realização de uma hierarquia entre os impulsos. Agir a partir do afeto do comando é experiência de liberdade: poder dizer Sim a tudo que aparece e afeta, e inclusive à insatisfação dos afetos, enquanto elemento, meio e condição de possibilidade do agir no sentido de um comando. Permanecer livre é permanecer atento e acompanhar o afeto do comando, a partir do qual se exerce a superioridade sobre a multiplicidade dos impulsos. Por isso, a liberdade é conquistada e renovada pelo exercício de um retesamento da atenção [Spannung der Aufmerksamkeit], uma concentração não apenas afetiva, mas também compreensiva, no sentido de discernir e distinguir. Chegar a distinguir algo até então indeterminado significa: ver eclodir do indeterminado uma determinação nova. $\mathrm{O}$ afeto do comando é, portanto, a dimensão da criação. Além disso, neste empenho de compreensão há necessariamente também uma compreensão do próprio empenho enquanto uma atividade imperativa. 
Vieira, R. P.

Consequentemente, o empenho por compreensão se desdobra em uma autocompreensão. Trata-se daquele reconhecimento que pode se expressar como um "eu sou livre - ele (isto é, algo em mim) tem de obedecer”. Assim, por fim e por último, a própria liberdade aparece na consciência e torna-se ela própria algo visível e distinto.

Pode-se comparar a consciência da liberdade à floração de um processo vital cujas raízes se assentam na obscuridade e estranheza do sentir e cujo tronco corresponde à firmeza do afeto do comando, cerne de todas as ramificações de sentimento e pensamento que a partir dele passam então a se articular. Todavia, não se trata aqui de um processo teleológico. O sentir não é de modo algum um instrumento ou uma mera etapa intermediária, nem a consciência da liberdade um produto, nem o afeto do comando um sujeito ou causa eficiente que fabrica a segunda através do primeiro. Não há hierarquia de importância entre estes elementos. Seu desenvolvimento não é linear, mas circular, tal como agora podemos perceber relendo aquela passagem decisiva da Genealogia da Moral que citamos na Introdução deste ensaio (GM/GM II, 2-3, KSA 5.294).

Aqui, é a consciência da liberdade que se desenvolve em consciência moral, e não o contrário. Não se trata de um conhecimento abstrato que serve de orientação teórica para a execução de uma prática, nem de controle ou coação exercida pela consciência sobre o corpo. Em vez disso, vimos que, uma vez experimentada a liberdade, ela emerge para a reflexão. Evidentemente, isso é o que possibilita realizar uma reflexão filosófica a respeito dela. Contudo, uma vez que é no âmbito da liberdade que aparecem "meta" e "linha reta", não é possível que a própria liberdade seja uma meta como qualquer outra. O que transparece na evidência da liberdade é, paradoxalmente, o oposto: que ela se encontrava velada no sentir da tempestade que conduziu a ela. Se o afeto do comando possibilita um concentrar-se em uma hierarquia que se autoclarifica criativamente $\mathrm{e}$ concede orientação determinada, o afeto da tempestade, por sua vez, 
O conceito de consciência moral como chave de uma interpretação...

requisitava uma concentração no estranhamento e distanciamento diante da ausência de hierarquia e determinação. $O$ fato de o segundo ser uma condição do primeiro não apaga a evidência de que o campo de visão e consciência do afeto da tempestade não se encontrava de modo algum determinado pelo afeto de comando, nem mesmo sob a forma de uma carência determinada. Por isso, a consciência da liberdade não dá ao homem o poder de executar a liberdade enquanto algo já sabido e sempre sob seu poder, nem lhe dá uma clareza perpétua e doravante sempre crescente de como afinar-se afetivamente com ela, mas, ao contrário, revela para ele sua condição de estar à mercê da liberdade enquanto o único instinto que provém, não da clareza de um afeto visível, mas da obscuridade do afeto de uma tempestade. É neste sentido que o saber da liberdade nunca é essencialmente um dado teórico da consciência - e portanto nunca é comunicável como um saber geral - nem permanece muito tempo relevante enquanto conhecimento, mas, precisamente à medida que é apreciado e considerado enquanto conhecimento, dissolvese no próprio paradoxo e provoca um relaxamento de tensão no âmbito do pensamento, irrigando pela sua experiência as camadas mais profundas do sentir. A eclosão do instinto de liberdade na consciência da liberdade, ao invés de um processo guiado pela consciência enquanto telos e pautado pelo conteúdo que nela se abre, consiste em um movimento de conquista da consciência pelo instinto. A dimensão mais própria do instinto, aquela em que ele não é determinado por algo aberto na consciência nem por uma abertura afetiva já claramente determinada, mas inversamente se apresenta como núcleo e raiz das possibilidades do sentir e do pensar, é aquela do impulso correspondente ao afeto da tempestade. O pensar correspondente a este âmbito, por sua vez, é a consciência da liberdade enquanto conhecimento desta experiência. ${ }^{6}$

6 Uma reflexão sobre este percurso também aparece em FW/GC 334, KSA 3.559.

Cad. Nietzsche, Guarulhos/Porto Seguro, v.40, n.1, p. 193-219, janeiro/abril, 2019. 
Vieira, R. P.

Nietzsche havia formulado: a vontade de potência é instinto de liberdade. Este é o instinto que abraça a tempestade e possibilita o raio do afeto de comando, que por sua vez ensina novamente a compreender a tempestade. Assim, o impulso condutor e criador deste círculo é a vontade de potência. O sentir da totalidade deste círculo é a consciência moral. E o aspecto de abertura de experiência e de campo de visão inerente ao círculo é o que Nietzsche chama de "vida". Por isso, a vida é o inestimável que condiciona e possibilita as estimativas de valor estipuladas no aparecer dos afetos sob o modo da hierarquia, que a vontade de potência instaura a cada vez no afeto de comando:

Seria preciso estar numa posição fora da vida e, por outro lado, conhecê-la como alguém, como muitos, como todos os que a viveram, para poder sequer tocar no problema do valor da vida. (...) Ao falar de valores, falamos sob a inspiração, sob a ótica da vida: a vida mesma nos força a estabelecer valores, ela mesma valora através de nós, ao estabelecermos valores... (GD/CI, Moral como contranatureza 5, KSA 6.86).

$\mathrm{O}$ circulo da vida é o âmbito em que realidade aparece e desaparece, segundo seu próprio dar-se ou retrair-se. Não é o homem que põe a realidade segundo sua subjetividade previamente constituída; tampouco ele é mero observador passivo. Os afetos se apresentam por si mesmos, embora caiba ao humano posicionar-se de determinado modo quanto ao que lhe aparece. $\mathrm{O}$ dar-se de realidade é determinado simultaneamente pela inspiração e ótica da vida, e pela postura e engajamento dos seres humanos que se constituem enquanto viventes. Tanto esta postura, radicada na relação com a consciência moral, quanto a inspiração e a ótica das perspectivas, que constituem vida, têm por essência, isto é, condição primordial de realização, a vontade de potência. Enquanto essência da vida, ela não equivale ao estar-vivo e ao horizonte a cada vez aberto e determinado pelo viver; antes, ela é o nascer e o morrer pelos quais o vivo emerge do não-vivo e a ele retorna. $\mathrm{O}$ não-vivo não é o morto nem o meramente

204 Cad. Nietzsche, Guarulhos/Porto Seguro, v.40, n.1, p. 193-219, janeiro/abril, 2019. 
O conceito de consciência moral como chave de uma interpretação...

inanimado entendido como desconexo e até antagônico em relação à vida. É a Terra. Esta palavra é o signo da finitude da vida enquanto horizonte insuperável de realidade, e portanto da condição humana de estar à mercê da inspiração e da ótica de suas perspectivas. Não é possível transcender a Terra e abarcar a própria vida enquanto algo disposto pelo afeto de comando e determinado em uma valoração contra tais esperanças supraterrenas, Zaratustra adverte. Limitando estas possibilidades, a Terra também se constitui em uma de suas condições. Porque a Terra está intimamente aparentada à vida e ao brilho do aparecer enquanto essência de todo valor, "o coração da Terra é de ouro" (ZA/ZA II, Dos Grandes Acontecimentos, KSA 4.170). Por sua vez, enquanto essência da vida, a vontade de potência é o princípio de integração ou desintegração entre vida e Terra.

À luz destas conexões entre os conceitos, torna-se possível compreender a seguinte anotação: “(...) a vontade de potência não é um ser [ein Sein], nem um devir [ein Werden], mas é um pathos que é o fato mais elementar [elementarste Thatsache], a partir de onde, originariamente, [aus der sich erst] um devir [ein Werden], um efeito [ein Wirken] se dá"7 (Nachlass/FP 1888, 14 [79], KSA 13.259)

Note-se de início que não se trata de uma descrição meramente psicológica da vontade de potência, circunscrevendo-a ao âmbito mais restrito da subjetividade humana, o qual precisaria então ser reconduzido ao âmbito mais amplo e objetivo da cosmologia. A vontade de potência é um pathos, um afeto. Não é, portanto, nada de exterior nem interior, mas situa-se naquela dimensão ontológica a partir da qual se pode, em um segundo momento e apenas abstratamente, estabelecer distinções entre exterior e interior. Pathos, afeto, é a conexão entre humano e real - ou, para ser mais preciso, é o lugar ontológico que antecede a separação a partir da qual se poderia falar em algo como uma conexão. Não obstante, não se trata aqui de um pathos qualquer, mas, especificamente, do pathos da possibilidade do

7 Tradução nossa.

Cad. Nietzsche, Guarulhos/Porto Seguro, v.40, n.1, p. 193-219, janeiro/abril, 2019. 
Vieira, R. P.

aparecer e vir a ser. Isto é, aquele pathos da tempestade, do qual pode eclodir o afeto do comando. É somente aqui que vontade de potência se mostra da maneira mais direta e radical, enquanto o instinto que impele a uma concentração nesta experiência e possibilita, a partir deste movimento, todo outro movimento de clarificação e realização. Neste sentido, este mesmo e específico pathos é o fato elementar e constituidor de toda experiência. É da estranheza tempestuosa duramente afirmada e suportada que eclodem os demais tipos de experiência, mais claros e distintos. Por isso, a vontade de potência pode ser formulada também assim: "A vontade de potência é a formaafeto primitiva [die primitive Affekt-Form], todos os outros afetos são apenas configurações [Ausgestaltungen] suas"8 (Nachlass/FP 1888, 14[121], KSA 13.300). Esta formulação vincula mais claramente a vontade de potência não apenas ao pathos a partir do qual um devir se dá, mas também aos afetos nos quais a clareza e simplicidade inerente a eles tende a fazer esquecer a experiência de obscuridade da qual eles provêm. Neste esquecimento, a consciência moral o sentir no interior do qual o afeto de comando pode vir a ser, o sentir que abarca tempestade e raio e movimento de iluminação se apaga enquanto uma experiência distinta e adormece. Lá onde a consciência moral não é experimentada, o próprio velamento encontra-se velado, e tudo parece esclarecido e dado pelos afetos que já se encontram abertos e amadurecidos. O próprio instinto de liberdade se enfraquece porque a liberdade começa a parecer algo já realizado; a vontade, originariamente livre e independente de uma orientação determinada, e portanto condição de possibilidade de criação de orientação, agora se acha subordinada e enclausurada apenas ao âmbito do já constituído. É por isso que a consciência da liberdade só se preserva de mal-entendidos se for atravessada de modo pensante e reconhecida como um paradoxo que a torna novamente problemática e por vir. Pensar, nesta acepção, é audácia de navegar tormentas - desejo de enigmas.

8 Tradução nossa.

$206 \mid$ Cad. Nietzsche, Guarulhos/Porto Seguro, v.40, n.1, p. 193-219, janeiro/abril, 2019. 
O conceito de consciência moral como chave de uma interpretação...

\section{Delimitação da má consciência frente à consciência moral}

Se, de início, parecia estranho postular um sentido para a noção nietzschiana de consciência moral que não estivesse vinculado à má consciência, agora, supondo que nossa interpretação até aqui se justifique, parece estranho precisamente o oposto: que a má consciência possa ter alguma coisa a ver com a consciência moral! No entanto, não pode haver dúvida quanto a esta conexão, e não apenas devido à proximidade lexical que, de outro modo, seria esdrúxula. Não obstante, antes de dar atenção aos termos nos quais a má consciência é diretamente exposta, há um breve aforismo que precisamos considerar a fim de localizar sua delimitação frente à noção mais ampla de consciência moral:

Medida e meio-termo - De duas coisas muito elevadas: medida e meiotermo, é melhor não falar nunca. Alguns poucos lhes conhecem as forças e acenos, a partir dos misteriosos caminhos das experiências e revoluções mais íntimas: honram nelas algo divino e têm pudor de levantar a voz. Todos os restantes quase não escutam quando delas se chega a falar, e acham que se trata de tédio e mediocridade: talvez com exceção daqueles que um dia entreouviram um ruído comprometedor proveniente daquele reino, mas o confrontaram tapando os ouvidos. A lembrança disto então os torna envilecidos e indignados ${ }^{9}$ (VM/OS 230, KSA 2.484)

O aforismo é uma análise de dois termos: Maass, medida, e Mitte, literalmente o meio, centro, cerne. Juntas, sugerem algo como meio-termo, comedimento, equilíbrio, centramento. Diz-se que são duas coisas tão elevadas que talvez fosse melhor não falar delas. Esta observação inicial já dá a entender que o sentido daquelas duas palavras não é o sentido cotidiano e nem mesmo um sentido propriamente teórico, mas um sentido que evoca experiências sem as quais ele será incompreensível, e portanto confundido com outra

9 Tradução nossa.

Cad. Nietzsche, Guarulhos/Porto Seguro, v.40, n.1, p. 193-219, janeiro/abril, 2019. 
Vieira, R. P.

coisa. É precisamente nesta direção que o texto avança, afirmando que alguns poucos podem compreender as palavras "medida" e "meiotermo" a partir das experiências e transformações mais íntimas e profundas; e, mesmo deste ponto de vista, tem-se apenas um aceno do que elas significam, isto é, apenas um sentir de forças que não se deixam descrever com precisão teórica. Assim, em vez de tentar defini-las, o texto aponta para as duas palavras através daquilo que despertam naqueles que as compreendem. Eles honram nelas algo divino e têm pudor de levantar a voz. Nisto reside o reconhecimento de algo que é digno de ser lembrado e preservado como orientação e referência. O pudor de levantar a voz significa uma compreensão da delicadeza das palavras, que exigem concentração para permanecerem claras e que podem facilmente ser mal-entendidas, sobretudo se forem banalizadas por um uso insensível. Assim, medida e meiotermo evocam alguma coisa que apareceu para o humano com o poder de fascinar e ordenar uma multiplicidade a partir de si. No entanto, trata-se de algo delicado e fugaz, que pode ser perdido de vista quase imperceptivelmente.

Toda esta caracterização evoca para nós aquilo que se descortina no interior do afeto do comando. Contudo, o mais interessante é que o aforismo prossegue apresentando duas outras maneiras pelas quais este mesmo fenômeno pode ser interpretado. Estas duas outras interpretações pertencem àqueles que de alguma maneira desconhecem a experiência indicada pelos termos medida e meiotermo. $\mathrm{O}$ sentido que este desconhecimento assume corresponde a alguma forma de esquecimento ou distração relativamente à memória desta experiência, uma vez que ela é constitutiva de toda experiência. Trata-se de um desconhecimento casual, inconsciente e involuntário. Medida e meio-termo soam como tédio e mediocridade. ${ }^{10}$ Tédio sugere uma repetição monótona. Tudo já foi obtido e fruído, e por isso já não mais atrai. $\mathrm{O}$ entediado gostaria que algo novo acontecesse, mas ele

10Sobre vontade de potência e tédio, $c f$. Nachlass/FP 1880, 4 [239], KSA 9.159).

208 | Cad. Nietzsche, Guarulhos/Porto Seguro, v.40, n.1, p. 193-219, janeiro/abril, 2019. 
O conceito de consciência moral como chave de uma interpretação...

não consegue encontrar algo novo em lugar algum. Isso o predispõe ao exótico, extremo, espalhafatoso ou mirabolante. Coisas deste gênero são tomadas por extraordinárias; meio-termo soa como mediocridade. Esta ambiência não é outra coisa senão uma insensibilidade para uma tempestade sufocada. A tempestade assume então outro modo de ser, a saber, de uma agitação barulhenta constantemente amortecida em qualquer teor contundente por um ater-se e concentrar-se no que quer que se encontre a cada vez aberto imediatamente na experiência, a despeito da força destas coisas rapidamente se esvair.

A esta altura, uma palavra central e outras em seu campo semântico sobressaem, estruturando todo o texto. Trata-se da escuta [hören]. Aqueles que compreendem as palavras "medida" e "meiotermo" evitam levantar a voz ou mencioná-las. Eles tomam-nas como estranhas e problemáticas, isto é, não apenas apreendem seu significado, mas ouvem o eco de seu modo de vir a ser e aparecer. Por sua vez, aqueles que não as compreendem "quase" [kaum] não escutam quando se fala delas. Com uma escuta frouxa do modo de ser, a visão do significado é indiferente. Por fim uma terceira interpretação das palavras aparece: nem daqueles que escutam, nem daqueles que simplesmente não escutam, mas daqueles que entreouviram um ruído comprometedor e o confrontaram tapando os ouvidos. Em certo sentido, este último tipo de interpretação é um subtipo daquela que consiste em não-escutar. Porém, trata-se de um não escutar ativo, de uma revolta contra a escuta, um agir no sentido de tapar os ouvidos. Mais intrigante ainda: este não escutar ativo só é possível porque uma escuta se deu, afetou, vulnerabilizou. O decisivo é que a postura humana diante deste fenômeno não é aquela de concentração, acolhimento e atenção, mas o oposto: é um recusar, abafar, não deixar aparecer. Aquilo que fora ouvido soou comprometedor [ahnmanenden], isto é, foi interpretado como algo que não deveria poder ser, que não estava autorizado a existir. Não obstante, o humano não tem o poder que pretende, isto é, o poder 
de se sobrepor ao poder do que aparece por si mesmo, moldando-o e reduzindo-o a suas projeções e planejamentos. Impotente, só lhe resta tapar os ouvidos, apesar da insistência do que então assume o modo de ser de um estranho ruído [Klang]. Devido à postura humana, aquelas palavras, ou antes as experiências e o sentido daquelas palavras, transformam-se em ruído invasor, ameaçador, desarmonizador. Com isso, cresce o afeto da indignação, mas uma indignação ontológica, ofendida pelo fato de a realidade ser o que é, e não o que deveria ser, e pela impotência humana de produzir o desaparecer daquilo que por si mesmo aparece, substituindo-o por um dever-ser artificial. Esta indignação envilece, transforma o humano em inimigo odiento do real.

Este aforismo é a raiz das três figuras ou tipos centrais da Genealogia da Moral: nobre, escravo (ou "vulgar", "comum", etc.) e sacerdote. Estas três figuras correspondem a três modos de escuta, isto é, modos de engajamento relativamente à consciência moral: afirmála, ignorá-la e negá-la. À afirmação corresponde, como já pudemos depreender, uma certa relação com a consciência moral cujo processo possibilita o acontecimento da eclosão do afeto de comando. Ignorar a escuta, por sua vez, pode ser entendido como uma distração, cujo teor fica mais claro, por exemplo, na seguinte passagem:

A natureza vulgar se caracteriza pelo fato de nunca perder de vista a sua vantagem e pelo fato de este pensamento de uma vantagem e finalidade ser até mais forte que os mais fortes impulsos nela existentes: não permitir que esses impulsos a desencaminhem para ações despropositadas - eis sua sabedoria e amor-próprio. Comparada a ela, a natureza superior é insensata: - pois o indivíduo nobre, magnânimo, que se sacrifica, sucumbe mesmo a seus instintos, e em seus melhores momentos sua razão faz uma pausa (FW/GC 3, KSA 3.374).

O tipo vulgar não tem ouvidos para seus próprios impulsos, mesmo os mais fortes. Um pensamento o orienta: aquele que prescreve uma vantagem e finalidade. Vantagem significa: algo prazeroso,

$210 \mid$ Cad. Nietzsche, Guarulhos/Porto Seguro, v.40, n.1, p. 193-219, janeiro/abril, 2019. 
O conceito de consciência moral como chave de uma interpretação...

confortável, inofensivo. Minimizar e se possível erradicar o sofrimento e a frustração; esta é a finalidade do agir vulgar. Certamente, por detrás deste pensamento há afetos e impulsos, que tornam os homens "escravos momentâneos do afeto e da cobiça" (GM/GM II, 3, KSA 5.296). São os impulsos projetados pelos afetos que se sobrepuseram àquele impulso mais profundo e misterioso, o único que se vincula, não a algo determinado e já aberto, mas ao tempestuoso e velado: o instinto de liberdade, a vontade de potência. $\mathrm{O}$ impulso determinado pela configuração visível dos afetos requer a conservação de seus parâmetros de orientação. Toda a vontade torna-se então dependente da conservação do que já se abriu anteriormente. Trata-se da desmedida do impulso de conservação. A desmedida consiste no fato de que a teimosia em ater-se aos impulsos vinculados ao real já aberto corresponde a um ater-se ao elemento mais fraco, ontologicamente debitário do impulso profundo ligado à tempestade e à liberdade. Consequentemente, tende-se a um contínuo enfraquecimento da capacidade de suportar os fenômenos tal como são e aparecem, e a um empenho progressivamente doentio em substituir o real por uma fantasia cristalizada e decrépita, cujas raízes são experiências outrora reais e pujantes, mas agora caducas. É o que se pode depreender de uma passagem extraordinariamente compacta e cheia de implicações, não apenas éticas, e ontológicas, mas também para um método de pensar: "Chamo de mentira não querer ver algo que se vê, não querer vê-lo tal como se vê (...). A mentira habitual é aquela com que se mente a si mesmo; mentir para o outros é, relativamente, uma exceção" (AC/AC 55, KSA 6.238.)

O nobre, por sua vez, arrisca ou sacrifica a conservação, sujeitase ao sofrimento e ao limite e incorpora-os como naturais, movido pelo que Nietzsche chama de "elevação", imagem que evoca leveza e ampliação de horizontes. ${ }^{11}$ Trata-se daquilo que acontece no âmbito

11 Cf. p.ex. FW/GC 285, KSA 3.527 e JGB/BM 40, KSA 5.57. A conexão entre elevação e o tipo nobre aparece p.ex. em JGB/BM 260, KSA 5.208.

Cad. Nietzsche, Guarulhos/Porto Seguro, v.40, n.1, p. 193-219, janeiro/abril, 2019. 
Vieira, R. P.

do afeto de comando: experiência de transformação e vir a ser de horizonte de orientação. Aqui, portanto, fica clara a natureza daquilo que pode obstruir a possibilidade da elevação: uma desmedida de impulso de conservação. A este impulso corresponde o afeto do medo. Esta correlação se torna ontologicamente determinante. Pois então o que é determinante é uma repulsa ao desconhecido e imprevisível enquanto componentes da experiência - precisamente o oposto da vontade de potência, a atração pelo mistério da liberdade. ${ }^{12}$ A meta do medo profundo é em última instância impossível e antinatural, a saber, anular a finitude, a mortalidade e a vulnerabilidade inerentes ao ser vivo.

Uma vez que se encontra fechado para a possibilidade da criação, o vulgar só pode se orientar a partir de pensamentos previamente constituídos e comunicados a ele pela comunidade. O tipo de vantagem pela qual terá preferência a cada vez terá sido veiculado por outro, tipicamente pela cultura ou tradição. Certamente, pode-se conceber que se trate de pensamentos originariamente nobres, vulgarizados e adaptados pela compreensão vulgar; mas, neste caso, haveria uma relação razoavelmente harmônica entre nobre e vulgar, pela qual o vulgar permaneceria "obediente" ao "mando" do nobre, isto é, preservador e discípulo da cultura que dele emana, ainda que sob a tensão constante de apropriar-se dela segundo interesses asfixiantes e decadentes, contrários às suas condições de possibilidade. Nesta relação, mantém-se tanto quanto possível aberta a via pela qual o nobre pode decair em vulgar e o vulgar pode transformar-se em nobre. As duas possibilidades de existência humana aí em jogo, elevação e decadência, não se encontram em um antagonismo radical, mas apenas em uma tensão natural. ${ }^{13}$

No entanto, há uma terceira possibilidade humana, estranha e problemática: "a natureza de uma aristocracia sacerdotal esclarece

12 A oposição entre vontade de potência e medo fora intuída já a primeira anotação a respeito dela: Nachlass/FP 1876, 23[63], KSA 8.425

13 Sobre o teor originalmente fluido deste par conceitual, $c f$. p.ex. JGB/BM 263, KSA 5.217.

212 | Cad. Nietzsche, Guarulhos/Porto Seguro, v.40, n.1, p. 193-219, janeiro/abril, 2019. 
O conceito de consciência moral como chave de uma interpretação...

por que precisamente aí as antíteses de valores puderam bem cedo interiorizar-se e tornar-se mais intensas" (GM/GM I, 6, KSA 5.265). Uma aristocracia sacerdotal: um tipo híbrido ${ }^{\mathbf{1 4}}$ entre nobre e vulgar, que ao mesmo tempo contrapõe nobreza e vulgaridade. $\mathrm{O}$ sacerdote é um tipo criador, mas rebelado contra a própria experiência de criação. Pretende apossar-se daquilo que nela se abriu para assim apossarse de suas condições de possibilidade e submetê-las ao interesse da conservação. $\mathrm{O}$ sacerdote torna-se, portanto, um catalisador e propulsor da vulgaridade, pois cria meios para alimentar a fantasia de que a superação da finitude é uma possibilidade humana. À medida que o nobre é testemunha e afirmador da finitude, e também fonte de imprevisto e instabilidade, o sacerdote o odeia e quer erradicá-lo enquanto possibilidade humana. Por detrás desta projeção de ódio sobre a figura do nobre, esconde-se uma autonegação, pois o próprio sacerdote conhece a experiência que abomina.

Neste sentido, "já se percebe com que facilidade o modo de valoração sacerdotal pode derivar daquele cavalheiresco-aristocrático e depois desenvolver-se em seu oposto" (GM I, 7, KSA 5.266). Esta força criadora de meios de obstrução e negação da criação é o ressentimento, o amargor pelo sofrimento e vulnerabilidade outrora intensamente experimentados como constitutivos de toda experiência a partir da experiência distintiva da nobreza. Assim:

Enquanto toda moral nobre nasce de um triunfante Sim a si mesma, já de início a moral escrava diz Não a um "fora", um "outro", um "não-eu" - e este Não é seu ato criador. Esta inversão do olhar que estabelece valores - este necessário dirigir-se para fora, em vez de voltar-se para si - é algo próprio do ressentimento: a moral escrava sempre requer, para nascer, um mundo oposto e exterior, para poder agir em absoluto - sua ação é no fundo reação (GM/GM I, 10, KSA 5.270).

Contudo, o outro é uma projeção de si mesmo e exteriorizá-lo é um recurso para afastar-se dele enquanto si mesmo. O outro é estranho,

14GM/GM III, 15, KSA 5.372.

Cad. Nietzsche, Guarulhos/Porto Seguro, v.40, n.1, p. 193-219, janeiro/abril, 2019. 
Vieira, R. P.

e portanto tido como ameaçador, mas estes mesmos atributos estão sempre também em si mesmo, e são eles que se gostaria de esconjurar. $\mathrm{O}$ ato criador do sacerdote, fantasioso e sedutor, é uma imagem de positividade absoluta, cujo significado subterrâneo não é a afirmação, mas a negação da negatividade constitutiva de toda positividade. Malgrado a lição da lógica, neste caso a negação da negação não equivale a uma afirmação, mas a uma potencialização exponencial da negação. Projetam-se imagens de negatividade absoluta para combater, com elas, toda e qualquer negatividade. Porém, a negatividade não cessa de emergir por si mesma, e o testemunho da nobreza não cessa de fazê-la brilhar como natural e inexorável. Um antigo fragmento de Heráclito pergunta: "Como alguém poderia manter-se encoberto face ao que nunca se deita?" (fragmento 16, 2005).

Precisamente este esforço de manter-se encoberto - talvez quase inconcebível ou monstruoso para o grego e muito mais próximo do cristianismo e da modernidade, embora não confinado a estes fenômenos históricos - é a má consciência. A negação da consciência moral, um exercício de recusa da escuta, um engajamento em não deixar a realidade aparecer por si mesma, mas substituí-la por uma projeção do pensamento humano segundo a qual a finitude seria abolida. No cerne da má consciência, uma recusa de si mesmo e de algo que já se viveu e experimentou, uma reação contra a própria experiência. Este esclarecimento já torna visível a conexão com “culpa e coisas afins". Nietzsche chega mesmo a perguntar: "Mas como veio ao mundo aquela outra 'coisa sombria', a consciência da culpa [Bewusstsein der Schuld], a 'má consciência' [schlechte Gewissen]?" (GM/GM, II, 4, KSA 5.297). Má consciência aparece quase como sinônimo de consciência da culpa, isto é, de determinação da culpa a partir da consciência que se fixa em um pensamento enquanto prescrição e dever-ser para todo o real. ${ }^{15}$ Observando com mais detalhe e minúcia, é mais exato afirmar que a consciência da culpa é o produto e instrumento da má consciência.

15Cf. GM/GM II, 3, KSA 5.294.

214 Cad. Nietzsche, Guarulhos/Porto Seguro, v.40, n.1, p. 193-219, janeiro/abril, 2019. 
O conceito de consciência moral como chave de uma interpretação...

Vejo a má consciência como a profunda doença que o homem teve de contrair sob a pressão da mais radical das mudanças que viveu - a mudança que sobreveio quando ele se viu definitivamente encerrado no âmbito da sociedade e da paz. (...) Para as funções mais simples sentiam-se canhestros, nesse novo mundo não possuíam mais os seus velhos guias, os impulsos reguladores e inconscientemente certeiros - estavam reduzidos, os infelizes, a pensar, inferir, calcular [Berechnen], combinar causas e efeitos, reduzidos à sua "consciência" [Bewusstsein], ao seu órgão mais frágil e falível! (GM/GM II, 16, KSA 5.321).

O âmbito da sociedade já estabelecida e cristalizada é o âmbito natural ao tipo vulgar, devido à crescente utilidade assumida pela consciência enquanto fixadora dos costumes que garantem a estabilidade e a conservação. Ambiente, assim, também propício para a ação do sacerdote. Pois este supervaloriza a consciência enquanto fundamento de toda orientação humana e em detrimento dos impulsos, à medida que sacraliza e dá profundidade ontológica ao costume tipicamente, mas não necessariamente, sob a forma da religião ${ }^{\mathbf{1 6}}-\mathrm{e}$ fixa então pela primeira vez a moral naquele sentido conhecidamente atacado por Nietzsche. A má consciência é, portanto, a postura fundamental de engajamento refratário ao aparecer espontâneo de realidade, que torna o ressentimento predominante e se projeta em uma consciência da culpa cujo conteúdo são os pensamentos que formam o conjunto das prescrições da moral vigente enquanto um dever-ser imposto à própria realidade.

\section{Conclusão}

$\mathrm{O}$ combate anunciado por Nietzsche à moral e à má consciência pode agora ser situado no âmbito de uma ética mais ampla e que conta com elementos não apenas críticos, mas também positivos. Pois, tal como antecipado na introdução deste ensaio, apresentaram-se argumentos para: 1) diferenciar consciência moral e má consciência e,

16Cf. M/A 9, KSA 3.21.

Cad. Nietzsche, Guarulhos/Porto Seguro, v.40, n.1, p. 193-219, janeiro/abril, 2019. 
Vieira, R. P.

2) identificar conexões essenciais entre consciência moral e vontade de potência. Resta pensar nosso terceiro ponto, a saber, a ideia de que má consciência e vontade de potência (à qual poderíamos, agora, associar a consciência moral) pudessem formar uma espécie de dilema ético. Combater a má consciência promovendo a consciência moral? Em um texto de seu período mais crítico, Nietzsche afirma explicitamente:

(...) para onde apontaremos nós as nossas esperanças? - Para novos filósofos, não há escolha; para espíritos fortes e originais o bastante para estimular valorizações opostas e transvalorar [umzuwerten] e transtornar [umzukehren] "valores eternos" (...). uma transvaloração dos valores, sob cuja nova pressão e novo martelo uma consciência moral se tornaria brônzea [ein Gewissen gestählt ] , um coração se faria de aço, de modo a suportar o peso de uma tal responsabilidade. (...) quem possui a rara percepção do perigo geral de que o próprio "homem" degenere (...), ele sabe, com todo o saber de sua consciência moral [mit allem Wissen seines Gewissen], como o homem está ainda inesgotado para as grandes possibilidades (...) (JGB/BM 203, KSA 5.126).

A tarefa dos pensadores contemporâneos não é meramente erodir criticamente os "valores eternos". A pressão do "martelo" da crítica tem por principal finalidade forjar uma nova consciência moral. Isso é decisivo, pois se a crítica permanece apenas no nível teórico e intelectual, sem tocar a afetividade e a postura humanas, não pode produzir nada genuinamente transformador. Significa: o ataque à moral enquanto conjunto de pensamentos dotados de valor prescritivo a ser refutado por outro conjunto de pensamentos não atinge o seu subterrâneo e força motriz, a saber, a má consciência. Esta só pode ser superada através de uma transformação da consciência moral. Somente esta transformação é uma transvaloração, isto é, não tanto ou prioritariamente uma mudança de conteúdo dos valores, mas de seu modo de ser.

Impõe-se o problema, portanto, de como cultivar esta transvaloração. Bem cedo Nietzsche já intuíra que a crítica e a transformação ao nível do pensamento não é suficiente, mas tem um valor preparatório importante:

$216 \mid$ Cad. Nietzsche, Guarulhos/Porto Seguro, v.40, n.1, p. 193-219, janeiro/abril, 2019. 
O conceito de consciência moral como chave de uma interpretação...

Não nego, como é evidente - a menos que eu seja um tolo -, que muitas ações consideradas imorais devem ser evitadas e combatidas; do mesmo modo, que muitas consideradas morais devem ser praticadas e promovidas - mas acho que, num caso e no outro, por razões outras que as de até agora. Temos que aprender a pensar de outra forma [umzulernen] - para enfim, talvez bem mais tarde, alcançar ainda mais: sentir de outra forma [umzufiuhlen]. (M/A 103, KSA 3.91).

Como promover a possibilidade de sentir de outra forma, se o sentir precisamente não é algo unilateralmente determinado pelo homem? Se a pretensão de prescrever um dever-ser ideal para o ser humano e para o real é justamente o problema a ser, em algum grau, superado? Se esta tarefa não pode, de modo algum, transformar-se em palavra de ordem, cartilha, doutrina? Sem dúvida há o perigo de um mal-entendido deste tipo. Porém, a má consciência - não é ela mesma também um fenômeno que agora nos aparece? Condená-la em si mesma e incondicionalmente não seria já - má consciência? ${ }^{17}$ Não é ela, portanto, paradoxalmente, alguma coisa a ser suportada e afirmada como constitutiva do ser humano e do real?

Ao invés de uma simples escolha entre duas opções predeterminadas, o decisivo para o problema de uma superação da má consciência é um demorado empenho em pensar estes estranhos fenômenos, pensar sem qualquer expectativa de resultado ou garantia de sucesso. Neste esforço de pensar de outro modo, há um esforço de desaprender (umzulernen). Desaprender, aprendendo a expor-se a possibilidades.

Se uma fenomenologia pode ser definida, utilizando os termos de Nietzsche, como precisamente o oposto de "não querer ver algo que se vê, não querer vê-lo tal como se vê". (AC/AC 55, KSA 6.238), então a fenomenologia da consciência moral abre para o pensamento o próprio fenômeno do querer ver e não querer ver, isto é, aquilo

17 Uma aproximação com este paradoxo parece surgir em GM/GM II, 24, KSA 5.335. Contudo, um reconhecimento deste problema em termos profundamente afetivos transparece em FW/GC 276, KSA 3.521.

Cad. Nietzsche, Guarulhos/Porto Seguro, v.40, n.1, p. 193-219, janeiro/abril, 2019. 
que Nietzsche chamou de "escuta". À medida que na escuta se oculta um "querer", pensar a escuta conduz a pensar a vontade de potência. Pensar a dinâmica de aparecer e ocultar-se que constitui o real, a partir da qual é possível ao ser humano atender à voz mais própria da consciência moral: "tu deves vir a ser o que tu és" (FW/ GC, 270, KSA 3.519).

\title{
The Concept of Moral Consciousness as a Key to a Phenomenological Interpretation
}

\begin{abstract}
The article intends to analyze Nietzsches concept of conscience (Gewissen), in order to show its connection to the will to power. This relation inscribes in its interior, as derived from it, the bad conscience (schlechtes Gewissen), and thus opens a phenomenological horizon of interpretation of the will to power. Keywords: conscience, phenomenology, bad conscience, will to power.
\end{abstract}

\section{Referências}

ANAXIMANDRO, PARMÊNIDES, HERÁCLITO. Os Pensadores Originários. Trad. Emmanuel Carneiro Leão e Sérgio Wrublewski. Bragança Paulista: Editora Universitária São Francisco, 2005.

BABICH, B. Nietzsche's Imperative as a Friend's Encomium: On Becoming the One You Are, Ethics, and Blessing. In: Nietzsche-Studien. Berlin/Boston: Walter de Gruyter, n.33, 2003, pp. 29-58.

DELEUZE, G. Nietzsche e a Filosofia. Trad. Antónimo Magalhães. Porto: RésEditora, 2001.

HEIDEGGER, M. Nietzsche, vol. I e II. Trad. Marco Antônio Casanova. Rio de Janeiro: Forense Universitária, 2007.

- Quem é o Zaratustra de Nietzsche? Trad. Gilvan Fogel. In: Ensaios e Conferências. Petrópolis: Vozes, 2006.

218 | Cad. Nietzsche, Guarulhos/Porto Seguro, v.40, n.1, p. 193-219, janeiro/abril, 2019. 
O conceito de consciência moral como chave de uma interpretação...

JASPERS, K. Introdução à filosofia de Friedrich Nietzsche. Trad. Marco Antônio Casanova. Rio de Janeiro: Forense Universitária, 2015.

KAUFMANN, W. Nietzsche: Philosopher, Psychologist, Antichrist. Princeton: Princeton University Press, 1974.

KRASTANOV, S. Nietzsche: Pathos artístico versus consciência moral. Jundiaí: Paco Editorial, 2016.

NIETZSCHE, F. A Gaia Ciência. Trad. Paulo César de Souza. São Paulo: Companhia das Letras, 2001.

. Além do Bem e do Mal: Prelúdio a uma Filosofia do Futuro. Trad. Paulo César de Souza. São Paulo: Companhia das Letras, 1993.

. O Anticristo. Trad. Paulo César de Souza. São Paulo: Companhia das Letras, 2007.

. Assim falou Zaratustra. Trad. Mário da Silva. Rio de Janeiro: Civilização Brasileira, 2002.

.Aurora. Trad. Paulo César de Souza. São Paulo: Companhia das Letras, 2004.

. Crepúsculo dos Ídolos. Trad. Paulo César de Souza. São Paulo: Companhia das Letras, 2006.

. Opiniões e sentenças diversas e $O$ andarilho e sua sombra. In: Humano, demasiado humano, vol. II. Trad. Paulo César de Souza. São Paulo: Companhia das Letras, 2008.

. Sämtliche Werke. Kritische Studienausgabe (KSA). Berlin/New York: Walter de Gruyter, 1999.

VISSER, G. "Du sollst der Werden, der du bist". Nietzsche gelezen in het licht van Zijn en Tijd. In: Tijdschrift voor Filosofie, Vol. 66, n. 3, 2004, pp. 499-527.

Artigo recebido para publicação em 03/02/2019

Artigo aceito para publicação em 06/03/2019 